\title{
Bacteriophage Sensitivity and Biochemical Group in Xanthomonas malvacearum
}

\author{
BY A. C. HAYWARD \\ Commonrealth Mycological Institute, \\ Ferry Lane, Kew, Surrey
}

(Received 26 November 1963)

\section{SUMMARY}

Isolates of Xanthomonas malvacearum, of which 18 representative cultures were examined in detail, were classified into two groups differing in: capacity to oxidize lactose, colony form on first isolation, proteolytic activity, and lysis by bacteriophages. The seven group 1 isolates examined in detail gave confluent lysis at routine test dilution by 7 of 13 phages isolated from diseased cotton plant material, and were weakly proteolytic and did not oxidize lactose in common with other group 1 isolates. All but one of the 11 group 2 isolates gave confluent lysis at RTD by the 6 phages to which the group 1 isolates were resistant but not by the other 7 phages. All isolates of group 2 oxidized lactose and were relatively strongly proteolytic. Phages active against $X$. malvacearum were detected in 87 out of 127 collections of infected leaves examined, and there was some correlation between the presence of groups 1 or 2 xanthomonads and the groupspecificity of the phage isolated from the same material. An isolate of group $2 X$. malvacearum which was resistant to some of the group 2-specific phages was apparently lysogenic.

\section{INTRODUCTION}

Xanthomonas malvacearum (E. F. Smith) Dowson, the cause of bacterial blight of cotton (Gossypium spp.), has been much studied from the pathological aspect but little as a subject for comparative bacteriological examination. Strains of the pathogen are known to occur which differ in pathogenicity for different varieties of cotton (Brinkerhoff, 1963), but it is not known whether such differences are correlated with characteristics of the pathogen determinable in the laboratory. As a first step isolates of $X$. malvacearum of diverse geographical origin were compared by using a variety of techniques including sensitivity to phages isolated from diseased cotton material, with a view to determining subspecific taxa. In this paper two groups of $X$. malvacearum are defined and their present known distribution is given.

\section{METHODS}

Bacteria and phages. Since October 1962212 collections of diseased cotton material or cultures of Xanthomonas malvacearum have been received for examination. Eighteen representative isolates (Table 1) were selected and examined in detail. For isolation and subcultivation sucrose $(2 \%)$ peptone agar was used (Hayward, 1960). On this medium cultures of $X$. malvacearum produced copious yellow mucoid growth after $2-3$ days at $25^{\circ}$ or $30^{\circ}$. All the phages used were isolated 
in this laboratory with the exception of phages $\mathrm{B} 648 \mathrm{P}, \mathrm{B} 649 \mathrm{P}$ and $\mathrm{B} 650 \mathrm{P}$, provided by C. Logan (formerly of the Cotton Research Station, Namulonge, Uganda). Leaf suspensions were enriched with a young liquid culture of the isolate of $X$. malvacearum previously obtained from the source material, and treated with chloroform following the technique of Crosse \& Hingorani (1958). It was later found to be unnecessary to enrich the suspension with a young culture of $X$. malvacearum or to make the suspension in a nutrient medium; the following technique was

Table 1. Sources of isolates of Xanthomonas malvacearum and phages

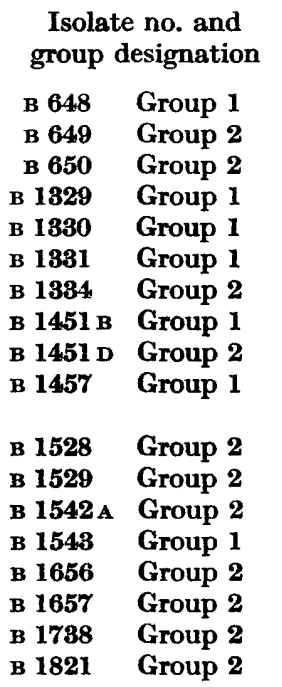

$\begin{array}{ccc}\text { Territory of origin } & \begin{array}{c}\text { Date of } \\ \text { isolation }\end{array} & \begin{array}{c}\text { Cotton material as } \\ \text { source of phage }\end{array}\end{array}$

Uganda (Namulonge)

Uganda (Kigumba)

Tanganyika (Ukiriguru)

Northern Nigeria (Katsina Province)

Northern Nigeria (Bauchi Province)

Northern Nigeria (Sardauna Province)

Sudan (Shambat)

Tanganyika (Nguduma)

Tanganyika (Nguduma)

Tanganyika (Ilonga)

United States, ATcc 9924

United States, ATCC 12132

Sudan (Kadugli)

Sudan (El Effein)

Uganda (Namulonge)

Uganda (Namulonge)

Australia (N.S.W.)

Kenya (Kibos)
Soil and leaf debris

Soil and leaf debris

Soil and leaf debris

Leaves

Leaves

Leaves

1962

1962

1963

1963

1945

1955

1963

1963

1963

1963

1963

1963
Leaves

Leaves

Cotton seed, leaves and stem

Leaves

Leaves

Leaves

Leaves

ATCC $=$ American Type Culture Collection, Washington 7, D.C., U.S.A.

adequate. Portions of heavily infected leaf material about $2 \mathrm{~cm} .^{2}$ were crushed with a glass rod in $10 \mathrm{ml}$. quantities of sterile distilled water, allowed to stand at room temperature for 24 or $48 \mathrm{hr}$, centrifuged, and $5.0 \mathrm{ml}$. of the supernatant fluid shaken vigorously with $0.5 \mathrm{ml}$. chloroform in a sterile $\frac{1}{4} \mathrm{oz}$. bottle. When the chloroform had settled about $0.02 \mathrm{ml}$. of suspension was pipetted on to the surface of pour plates of $X$. malvacearum. Phages were purified by streaking from single plaques on pour plates at least three times in succession. Titres of purified phage suspensions obtained by lysis of $24 \mathrm{hr}$ liquid cultures followed by centrifugation at $2500 \mathrm{~g}$ for $15-20 \mathrm{~min}$. were in the range $10^{9}$ to $5 \times 10^{10}$ phage particles $/ \mathrm{ml}$. suspension. For phage assays the agar medium of Crosse \& Hingorani (1958) was used, adjusted to $\mathrm{pH} 7 \cdot 2$ with $40 \% \mathrm{NaOH}$. The same medium without agar was used for propagation of phage in liquid culture. Oxoid agar No. 3 (Oxo Ltd., London) at $1 \%$ (w/v) was used in the solid medium, $15 \mathrm{ml} . / 9 \mathrm{~cm}$. diam. Petri dish for pour plates. Phages stored over chloroform (0.1-5 ml. suspension) were diluted to $10^{-7}$ in phage liquid medium and Pasteur pipettes delivering about 50 drops $/ \mathrm{ml}$. were used to add phage suspensions to the surface of pour plates dried open at $37^{\circ}$ for $2 \mathrm{hr}$. All phage assay tests were carried out at $25^{\circ}$.

Physiological tests. The methods used were those described previously (Hayward \& Hodgkiss, 1961; Hayward, 1962) with modifications described below. Nitrate 
and nitrite reduction tests were made at 6 days, the concentration of sodium nitrite being lowered to $0.01 \mathrm{~g} . /$. For detection of urease activity the method of Christensen (1946) was used, cultures being incubated for 14 days; for detection of lipolytic activity, the method of Sierra (1957) with Tween 80 (Honeywill Atlas Ltd.). For determination of the egg yolk reaction, Oxoid nutrient agar No. 2 (cM 2) was supplemented with glucose $(10 \cdot 0 \mathrm{~g} . / 1$.$) and sodium chloride (5 \cdot 0 \mathrm{~g} . / \mathrm{l}$.$) . Oxoid sterile$ egg yolk $(5 \mathrm{ml}$.) was added to $50 \mathrm{ml}$. molten cooled basal medium, and three plates poured. After incubation for 4 days the surface growth was wiped away and the agar beneath the confluent growth examined for changes due to lipase or lecithinase activity. Growth at $37^{\circ}$ was determined by inoculation from a pipette or with a loop from agar growth on to slopes incubated in a water bath; the latter technique gave more consistent results. For assay of starch hydrolysis a densely opaque suspension was inoculated with a $3.0 \mathrm{~mm}$. diam. wire loop to the centre of cavities cut in soluble starch agar plates with a No. 2 cork borer. After $42 \mathrm{hr}$ at $28^{\circ}$ plates, each with three cavities and inoculated with three isolates, were flooded with Gram's iodine solution and zones of hydrolysis measured (Hayward, 1962). Casein and gelatin plates inoculated from a light suspension in sterile water were examined at 3 and 6 days. The surface growth was wiped away with cotton wool and gelatine plates were flooded with acid mercuric chloride solution (Frazier, 1926) to determine areas of hydrolysis. On casein agar plates areas of clearing were observed. The method for determination of carbohydrate oxidation reactions in a $0.1 \%$ peptone bromothymol blue medium was described by Hayward (1962); tubes were discarded after incubation for 21 days. A dense pellicle of yellow surface growth and acid reaction $0.5 \mathrm{~cm}$. beneath the surface growth was recorded as a positive reaction. Carbohydrate media and liquid media were inoculated with 2-3 drops of a light distilled-water suspension from a Pasteur pipette. Oxidase activity was examined by the method of Kovacs (1956) with $48 \mathrm{hr}$ growth on Oxoid nutrient agar No. 3 (CM 3). Gelatin stab cultures were made in the following medium: Oxoid bacteriological peptone, 5.0 g.; Difco yeast extract, 3.0 g.; gelatine (British Drug Houses Ltd.), $120 \cdot 0$ g.; distilled water, 11 .; to $\mathrm{pH} 7 \cdot 0-7 \cdot 4$ with $40 \% \mathrm{NaOH}$. Sterilization was by autoclaving $10 \mathrm{ml}$. volumes in $1 \mathrm{oz}$. bottles at $121^{\circ}$ for $15 \mathrm{~min}$.

\section{RESULTS}

The characteristics of the 18 isolates of Xanthomonas malvacearum are summarized in Table 2. Eleven of the isolates were consistently positive for lactose oxidation, the other seven consistently negative in repeated examinations. The lactose-positive isolates differed from the lactose-negative cultures in rate and extent of hydrolysis of casein and gelatine. In the latter group, at 3 days on casein agar, no zone of clearing was observed when the confluent growth was wiped away. At 6 days there was a zone of clearing confined to the boundary of the confluent growth, whereas lactose-positive cultures produced a zone of clearing extending for several mm. beyond the confluent growth at 2-4 days of incubation. Similarly, on gelatin agar, lactose-positive cultures hydrolysed gelatin more rapidly than lactose-negative cultures, the same difference being apparent in gelatin stab cultures. At 10 days there was no liquefaction or a drop of liquid only at the surface of the lactosenegative cultures; by contrast the lactose-positive cultures produced a zone of 
liquefaction 5.0-10.0 mm. in depth. In general these differences in proteolytic activity were reproducible and were invariably according to group in freshly isolated cultures, provided that the casein and gelatin agar media were inoculated from light suspensions in distilled water. The difference in proteolytic activity was less clear-cut, or not apparent, when agar media were heavily inoculated with a wire loop from agar growth. In addition some lactose-negative cultures maintained on artificial media apparently acquired increased proteolytic activity, and one lactosenegative strain maintained on artificial medium for 11 years was comparable in proteolytic activity to lactose-positive cultures, although otherwise unchanged in characters typical of this group. There was no correlated difference in starch hydrolysis; the 18 isolates produced clearly defined zones of hydrolysis of diameter 20.0-25.0 mm. (mean value $22.5 \mathrm{~mm}$.) at $42 \mathrm{hr}$.

\section{Table 2. Characterisics of 18 isolates of Xanthomonas malvacearum}

Positive

Motility

Mucoid, yellow growth on sucrose peptone agar

Aesculin hydrolysis

$\mathbf{H}_{2} \mathrm{~S}$ production

Starch hydrolysis

Growth at $37^{\circ}$ *

Tween 80 hydrolysis

Oxidation of glucose, mannose,

fructose, sucrose, arabinose, galactose, maltose, cellobiose, dextrin, raffinose $\dagger$, glycerol, melibiose $\uparrow$, xylose
Variable

Lactose (11 strains consistently positive, 7 consistently negative)

Casein and gelatin hydro-

lysis (11 strains strongly positive, 7 weakly positive) Mannitol $\dagger$ (11 strains consistently negative, 7 strains variable reaction at different times of testing)

Egg-yolk reactionł
Negative

Urease
Nitrite from nitrate
Nitrite destruction
Indole
Acetoin
Oxidation of inulin, dulcitol,
sorbitol, $\alpha$-methyl-p-
glucoside, mesoinositol,
salicin, rhamnose, erythritol,
sorbose
Kovacs oxidase test (at 5-10
sec.)

Urease

Indole

sorbitol, $\alpha$-methyl-Dglucoside, mesoinositol,

salicin, rhamnose, erythritol, sec.)

* Growth at $37^{\circ}$ erratic except from heavy inoculum.

$\dagger$ B 1451 B and B $1451 \mathrm{D}$ negative in raffinose medium; some other strains give a late partial reaction. B 1451 B negative in melibiose medium. The seven cultures variable in mannitol oxidation were all group 1.

¥ Reaction varied according to composition of the medium (see text).

All 18 isolates of Xanthomonas malvacearum were negative in the Kovacs oxidase test at 5 sec. In a minority of isolates there was a trace reaction in 5-10 sec., but all were positive in 10-60 sec. Aesculin was hydrolysed by all strains in 4-8 days, and lipolytic activity in the Tween 80 medium was apparent in 2-4 days of incubation. The test for gluconate oxidation was negative or weakly positive (trace of orange precipitate, with blue suspension) at 7-10 days, in agreement with the results of Dye (1962) for the genus Xanthomonas. In Oxoid nutrient agar supplemented with glucose and sodium chloride none of the cultures produced any change in the egg-yolk medium, which was initially clear, after incubation for 4 days. However, when the test was repeated with the basal medium for detection of hydrolysis of Tween 80 (Sierra, 1957), which became opaque on addition of sterile egg-yolk emulsion, all isolates of group 1 produced a zone of clearing and then a densely opaque zone of precipitation extending from the margin of the confluent bacterial growth during incubation for 2-4 days. Group 2 isolates produced no change in the medium at 4 days. The difference in reaction between group 1 and 2 isolates on an opaque egg-yolk medium is potentially of diagnostic 
value but has yet to be confirmed on a larger collection of isolates. Slight differences in colony form between lactose-negative and lactose-positive cultures were apparent in 2- to 3-day cultures at 25 or $30^{\circ}$ on sucrose peptone agar on first isolation. Lactose-negative cultures (group 1) when viewed by transmitted light with the naked eye showed a finely striate texture. This character was best seen in $40-48 \mathrm{hr}$ cultures at $80^{\circ}$ or in $60 \mathrm{hr}$ cultures at $25^{\circ}$; the appearance was less distinct in older cultures. Lactose-positive cultures were homogeneous when examined in the same way and were less convex than group 1 colonies, which were in general of a more mucoid consistency and sometimes of a deeper yellow than group 2 colonies. These differences were of great value in the screening of isolation plates for the presence of group 1 or 2 colonies, but they were lost on serial transfer on sucrose peptone agar due to the enhancement of mucoid consistency in group 2 isolates on this medium, and to the occurrence of colony variants.

The plaques formed by phage isolates on the propagating strains of Xanthomonas malvacearum were generally clear circular with entire margins, and were 3.0-5.0 mm. diam. after $24 \mathrm{hr}$ at $25^{\circ}$. Growth of resistant colonies in areas of lysis varied with the phage and propagating strain but they appeared only on prolonged incubation in some cases. Rosberg \& Parrack (1955) did not detect the growth of resistant colonies of $X$. malvacearum until 12 days had elapsed, when lysed liquid cultures were poured on to the surface of potato glucose agar plates. Other workers have commented on the size and regularity of the plaques formed by phages active on Xanthomonas species. For example, the phage for $\boldsymbol{X}$. phaseoli var. fuscans described by Klement \& Lovas (1960) produced plaques of 5.0-6.0 mm. diam. at 18-20 hr in a semi-solid agar medium. Mandell \& Eisenstark (1953), however, found that the size and form of plaques produced by $X$. pruni phages were markedly affected by such factors as temperature, age of inoculum, concentration of plating bacteria and salt concentration.

The activity of 14 bacteriophages at routine test dilution $\left(10^{-5}\right.$ dilution of a suspension containing $10^{9}$ to $5 \times 10^{10}$ phage particles $/ \mathrm{ml}$.) on the 18 cultures of Xanthomonas malvacearum is shown in Table 3. There is a correlation between phage sensitivity and biochemical group. Phages lysing isolates of group 1 lysed all other group 1 strains and none of group 2, whereas phages lysing group 2 cultures were inactive on group 1 isolates with the exception of isolate $B$ 1548. With this isolate, small discrete plaques were obtained at the routine test dilution with three of the six group 2-specific phages. The reactions obtained with undiluted suspensions were less clear cut. Some of the group 2 cultures gave discrete plaques when tested against the undiluted group 1-specific phages. Another effect, distinct from confluent lysis due to multiplication of phage, was observed with many high-titre suspensions on cultures which were unaffected at the RTD. Clear zones of lysis were obtained, but, unlike true phage lysis, the zone did not extend in diameter on further incubation and the area of lysis was restricted to the zone of adsorption of the drop of phage suspension. At $10^{-1}, 10^{-2}$ and $10^{-3}$ dilutions the effect became progressively less clear cut and ultimately faded out without the intermediate formation of discrete plaques. This effect was interpreted to be either lethal adsorption or bacteriocin activity; the former explanation was indicated by the following experiment. All 18 cultures of $X$. malvacearum were grown for 3 days in $10 \mathrm{ml}$. phage liquid medium, centrifuged, and $5 \mathrm{ml}$. quantities of supernatant fluid shaken 
with $0.1 \mathrm{ml}$. chloroform. About $0.02 \mathrm{ml}$. of each suspension was then added to pour plates of the cultures of $\boldsymbol{X}$. malvacearum. No zones of inhibition of growth were observed, showing that inhibition by high-titre phage suspensions was due to lethal absorption. Isolate $B$ 1334, a group 2 isolate which was resistant to two of the group 2-specific phages and partially susceptible to the other four was shown in this experiment to be apparently lysogenic. Numerous small discrete plaques of $0.5-$ $1.0 \mathrm{~mm}$. diam. were formed by isolate $B$ 1334 on six of the group 2 cultures (B 649, B 650, в 1821, в 1657, в 1738, в 1656) but none of the cultures of group 1 was lysed by the suspension.

Table 3. Lytic activity of 14 phages at routine test dilution on 7 isolates of Xanthomonas malvacearum group 1 and 11 isolates of $X$. malvacearum group 2

\begin{tabular}{|c|c|c|c|c|c|c|c|c|c|c|c|c|c|}
\hline \multicolumn{14}{|c|}{ Phage } \\
\hline 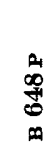 & 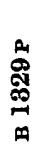 & 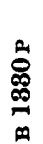 & $\underset{m}{\stackrel{0}{\infty}}$ & 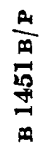 & 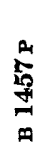 & 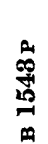 & 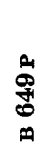 & $\begin{array}{l}0 \\
\text { \&: } \\
0 \\
0 \\
\text { m }\end{array}$ & 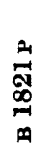 & $\underset{\infty}{\frac{B}{A}}$ & $\underset{\infty}{\stackrel{8}{8}}$ & 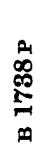 & 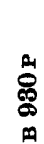 \\
\hline
\end{tabular}

\begin{tabular}{|c|c|c|c|c|c|c|c|c|c|c|c|c|c|c|}
\hline \multirow{2}{*}{$\begin{array}{c}\text { X. malva- } \\
\text { cearum } \\
\text { isolates }\end{array}$} & \multicolumn{14}{|c|}{ Territory of origin(*) } \\
\hline & $\mathbf{U}$ & $\mathbf{N}$ & $\mathbf{N}$ & $\mathbf{N}$ & $\mathbf{T}$ & $\mathbf{T}$ & $\mathbf{S}$ & $\mathbf{U}$ & $\mathbf{T}$ & $\mathbf{K}$ & $\mathbf{T}$ & $\mathbf{U}$ & $\mathbf{A}$ & NY \\
\hline \multicolumn{15}{|l|}{ Group 1} \\
\hline B 648 & CL & CL & CL & CL & CL & CL & CL & - & - & - & - & - & - & - \\
\hline В 1829 & CL & CL & CL & CL & CL & CL. & CL & - & - & - & - & - & - & - \\
\hline в 1330 & CL & CL & CL & $++t$ & CL & CL & CL & - & - & - & - & - & - & - \\
\hline B 1331 & CL & CL & CL & CL & CL & CL & CL & - & - & - & - & - & - & - \\
\hline B 1451 B & CL & CL & CL & CL & CL & CL & CL & - & - & - & - & - & - & - \\
\hline B 1457 & CL & CL & CL & CL & CL & CL & CL & - & - & - & - & - & - & - \\
\hline B 1543 & CL & CL & CL & CL & CL & CL & CL & $(++)$ & +++1 & - & $(++)$ & - & - & - \\
\hline \multicolumn{15}{|l|}{ Group 2} \\
\hline В 649 & - & - & - & - & - & - & - & CL & CL & CL & CL & CL & CL & - \\
\hline B 650 & - & - & - & - & - & - & - & CL & CL & CL & CL & CL & CL & +++ \\
\hline B 1821 & - & - & - & - & - & - & - & CL & CL & CL & CL & CL & CL & $++t$ \\
\hline B 1451 D & - & - & - & - & - & - & - & $\mathbf{C L}$ & CL & CL & $\mathbf{C L}$ & CL & CL & +++ \\
\hline B $\mathbf{1 6 5 7}$ & - & - & - & - & - & - & - & CL & CL & CL & CL & CL & CL & $+t+$ \\
\hline B $\mathbf{1 7 3 8}$ & - & - & - & - & - & - & - & CL & CL & CL & CL & CL & CL & +++ \\
\hline B $1542 \mathrm{~A}$ & - & - & - & - & - & - & - & CL & CL & CL & CL & CL & CL & - \\
\hline B 1528 & - & - & - & - & - & - & - & CL & CL & CL & CL & CL & CL & - \\
\hline B 1529 & - & - & - & - & - & - & - & CL & CL & CL & CL & CL & CL & - \\
\hline В 1656 & - & - & - & - & - & - & - & CL & CL & CL & CL & CL & CL & +++ \\
\hline B 1334 & - & - & - & - & - & - & - & $++t$ & SCL & $++t$ & $(+++$ & ) - & - & - \\
\hline
\end{tabular}

* U, Uganda; N, Nigeria; T, Tanganyika; S, Sudan; K, Kenya; A, Australia; NY, Nyasaland. CL, Confluent lysis; SCL, Semi-confluent lysis; - , no confluent lysis or discrete plaques; ++ , +++ , numerous large discrete plaques $(>1.0 \mathrm{~mm}$. diam. $) ;(++),(+++)$, numerous small discrete plaques $(<\mathbf{0 . 5} \mathbf{~ m m}$. diam.).

A total of 260 isolates from the 212 collections received was examined for the correlation between biochemical group and lysis by phages; 104 isolates were classified as group 1 and 156 as group 2. All but three of the group 1 isolates gave confluent lysis at the RTD with the group 1-specific phages with which they were tested, and not with the group 2-specific phages. Two of these three aberrant isolates had been maintained on artificial medium for more than 10 years. All three were 
resistant to one or other of the group 1-specific phages. Some other cultures which were typical of group 1 on first isolation showed a tendency to become resistant to group 1 phages as evidenced by an increase in the opacity of areas of confluent lysis when they were retested after several months on artificial medium. The isolates classified as group 2 included many which on first isolation and in repeated tests were resistant to one or other or all of the group 2-specific phages (e.g. isolate B 1334; see Table 3). Such differences may provide the basis for subdivision of group 2 isolates.

Experiments were made to determine the sensitivity of other Xanthomonas species to six representative $X$. malvacearum phages and the sensitivity of 18 $X$. malvacearum isolates to phages isolated from plant material infected with other plant pathogens. Four group 1-specific phages (B 648 P, в 1329 P, в 1330 P, в 1381 P) and two group 2-specific phages (B 649 P, B 650 P) were tested at high titre (0.02 ml. of a suspension containing $10^{9}$ to $5 \times 10^{10}$ phage particles $/ \mathrm{ml}$.) on pour plates of 50 xanthomonads representing 20 known species and 3 undescribed species. The bacteria tested were the following: $X$. phaseoli f.sp. sojense (9 strains), $X$. hederae (1), X. citri (1),X. papavericola (1), X. campestris (3), X. phaseoli (4), $X$. ricini $(4), X$. cyamophagus $(1), X$. vignicola $(2), X$. cassiae $(1), X$. punicae (1), $X$. khayae (1), X. patelii (1), X. cyamopsidis (1), X. vasculorum (2), X. phaseoli var. fuscans (4), $X$. sesami (2), $X$. desmodii-rotundifolii (1), $X$. nigromaculans f.sp. zinniae (3), $X$. pruni (2), five isolates of unidentified Xanthomonas spp. The six $X$. malvacearum phages were without macroscopic effect on 38 of the isolates. With the remaining twelve isolates zones of inhibition of growth were observed which appeared to be due to lethal adsorption and not to phage replication. When cultures representative of these twelve isolates were tested against dilutions of the six phages the zones of inhibition of growth became progressively less clear cut and ultimately faded out without the appearance of discrete plaques. Undiluted high titre suspensions of two $X$. pruni bacteriophages and one each for $X$. vasculorum, $X$. cassiae, $X$. campestris, $X$. citri, $X$. phaseoli and $X$. phaseoli var. fuscans did not produce confluent lysis or discrete plaques on the 18 cultures of $X$. malvacearum listed in Table 1. When some of these high-titre suspensions were diluted to $10^{-1}$ and $10^{-2}$, however, scattered discrete plaques of 1.0-1.5 mm. diam. were formed on some isolates of group 2. This suggests that undiluted lysates contain an inhibitor of the development of host-range mutants or that such mutants are inhibited by the majority of phage particles not capable of growth on the bacterium.

Four isolates of phages active against Xanthomonas phaseoli f.sp. sojense, isolated from soya bean leaves showing symptoms of bacterial pustule infection, were tested. Two were without effect but the other phages (B 998 P and в 930 P) gave confluent lysis of some group 2 isolates of $X$. malvacearum. Phage в 930 P was diluted and tested at the RTD: with six of the eleven group 2 isolates this phage gave numerous discrete plaques but the suspension was without activity on the seven group 1 cultures (Table 3). These experiments suggest that bacteriophages for $X$. malvacearum are highly specific and that isolates of this Xanthomonas species are in general not susceptible to lysis by phages isolated from hosts other than cotton infected with various Xanthomonas species.

Seed, stems, or leaves of cotton infected with Xanthomonas malvacearum frequently contain phages active against the bacterial pathogen. Material infected 
with group $1 X$. malvacearum may contain a phage active against this group only, and similarly cotton material infected with group $2 X$. malvacearum may contain a group 2-specific phage. Material infected with xanthomonads of both groups has been shown to contain two phages, which show group 1 and 2 specificity, respectively. This consistency of phage presence in bacterial blight-infected cotton material is illustrated in the experiments described below. In the first experiment 20.0 g. quantities of eight seed samples from Tanganyika were added to $100 \mathrm{ml}$. quantities of phage liquid medium in $350 \mathrm{ml}$. conical flasks. To each suspension $10 \mathrm{ml}$. cultures of an isolate of $X$. malvacearum group 1 (в 1457) and an isolate of

Table 4. Lytic activity of chloroform-treated suspensions derived from cotton seed washings

$\begin{array}{lcc}\text { Seed sample } & \begin{array}{c}\text { Activity on group 1 } \\ \text { isolate B 1457 }\end{array} & \begin{array}{c}\text { Activity on group 2 } \\ \text { isolate B 1451 D }\end{array} \\ \text { UKA G 2.1/17/904 } & \text { CL } & - \\ \text { UKA 59/209 } & \text { CL } & ++ \\ \text { UKA 59/206 } & \text { CL } & - \\ \text { UKA 59/488 } & \text { CL } & - \\ \text { UKA 59/494 } & \text { CL } & + \\ \text { UKA 59/513 } & \text { CL } & - \\ \text { UKA 59/515 } & \text { CL } & - \\ \text { IL 47/10 } & \text { CL } & -\end{array}$

CL, Confluent lysis;,++++ , discrete plaque formation.

group 2 (B $1451 \mathrm{D}$ ) were added. After incubation overnight at $25^{\circ}$ the seed liquor was centrifuged and $5 \mathrm{ml}$. quantities of supernatant fluid added to $0.2 \mathrm{ml}$. chloroform in sterile $\frac{1}{\mathrm{oz}}$. bottles. After vigorous shaking drops of chloroform-treated supernatant fluid were added to pour plates of the two xanthomonad isolates used for enrichment. The results given in Table 4 show that all the seed samples contained a phage active against group 1 and two of them also contained phages active against group 2 though in smaller numbers. The phages from UKA 59/209 and UKA 59/494 which lysed the group 2 isolate (B $1451 \mathrm{D}$ ) were isolated and purified by propagation on the same culture. At high titre neither phage exhibited activity against group 1 isolates. However, the presence of the bacterial pathogen in the seed samples could not be confirmed by isolation because of the rapid overgrowth of isolation plates with yellow, swarming, fast-growing saprophytic bacteria. In other experiments portions of cotton leaves from 127 heavily infected collections were suspended in 10-20 ml. sterile distilled water in 1 oz. bottles. After 1-6 days at room temperature about $5 \mathrm{ml}$. of the leaf liquor was added to $0.3-0.5 \mathrm{ml}$. chloroform, shaken vigorously, allowed to settle and drops added to the surface of separate pour plates of a group 1 isolate and of a group 2 isolate. After $24-48 \mathrm{hr}$ at $25^{\circ}$ the plates were examined for the presence of one or more discrete plaques. Forty-one of the 52 collections from which group 1 only had been isolated contained phages active against the group 1 isolate with which they were tested, but phages active on group 2 were not detected. Twenty-nine of the 63 collections containing group $2 X$. malvacearum contained phages active against the group 2 isolate with which they were tested; 4 were active on group 1 only and three were active on both groups. Twelve collections were examined which contained both group 1 and group $2 X$. 
malvacearum, and of these nine were active on group 1 only, none were active on group 2 only, and one was active on both groups. The majority of the collections were examined for the presence of phages 1-6 months after the date of collection, having been stored at room temperature in the period after collection.

The lack of correlation in some cases between the specificity of the phage and the xanthomonad isolated may partly be explained by the fact that some of the leaves were infected with organisms of both groups or that different leaves of the same collection were infected with group 1 or group 2 organisms; this has been shown to be so in some cases. The method described above assumes that any group 1 or group 2 isolate that has been shown to be susceptible to all the isolated phages of corresponding specificity will be adequate for the detection of phages in cotton leaves. However, this is not always the case; for example, chloroform-treated extracts prepared from eleven collections of leaves from Thailand, from each of which group 1 xanthomonads had been previously isolated, did not lyse the group 1 isolate $\mathrm{B} 1451 \mathrm{~B}$, which in other experiments had proved adequate for the detection of group 1-specific phages. When the same extracts were tested on pour plates of one of the group 1 isolates obtained from this group of eleven collections, nine of them gave confluent lysis.

\section{DISCUSSION}

There are other reports of the occurrence of virulent phages in cotton plant material infected with Xanthomonas malvacearum (Lagière, 1960, pp. 37-40), but these reports cannot be related to the present work because the phages described and their propagating strains were not available for comparison. Rosberg \& Parrack (1955) isolated a phage from 2-year-old dried diseased cotton leaves, but were unable to isolate similar phages from fresh collections from the field or the greenhouse. The factors leading to the appearance and distribution of phages on cotton material are not understood. Such phages are presumably virulent mutants of temperate phages. In view of the consistent occurrence of phages on cotton it is possible to speculate that they have a role in the reduction of disease incidence in the field, in modification of the intensity of epidemics or in the reduction of numbers of the bacterial pathogen in moribund leaves or trash remaining after harvest, but the fact that the bacterial pathogen can be isolated readily from leaves heavily infected with phage indicates that this effect is localized.

Experience in this laboratory has shown that bacterial blight of cotton is not an isolated example of a disease in which predation of the pathogen by a virulent phage is a common occurrence. Recently phages active against Xanthomonas citri, $X$. phaseoli, X. cassiae, X. campestris, X. ricini, $X$. phaseoli var. fuscans, and $X$. vasculorum have been isolated from host plant material for each of these pathogens. If it can be demonstrated as shown above for $X$. malvacearum, that such phages are specific for their bacterial hosts, then detection of phage in moribund plant material may be used as an alternative to isolation of the bacterial pathogen in diagnosis. The survival period (dry life) of phages, in common with that of other viruses, would be expected to be greater than that of bacteria. Although an aged specimen may be devoid of the bacterial pathogen, detection of the specific phage would enable a retrospective diagnosis to be made. In the case of bacterial blight of cotton the detection of phages active against $X$. malvacearum groups 1 and 2 in 
cotton material is strong presumptive evidence of active infection by either or both groups, or of a previous infection in material in which the bacterium is no longer viable or could not be detected by conventional plating methods. Such a method would be an alternative to the method described by Katznelson \& Sutton (1951) for the demonstration of internally borne bacterial infections of seed, but is likely to be of less wide application.

Diseased plant material is known to be a source of phages active against plant pathogenic bacteria. Phages for Xanthomonas translucens have been isolated from cereal seed (Sutton \& Katznelson, 1953), for $X$. phaseoli var. fuscans from bean seed (Klement, 1957), for $\boldsymbol{X}$. carotae from leaves and inflorescences of carrot, and for $X$. vesicatoria from diseased fruit or leaves of pepper and tomato (Klement, 1959). A bacteriophage active against numerous species of Xanthomonas has been described (Sutton, Katznelson \& Quadling, 1958), but other phages for species of this genus on which a detailed study of host range has been carried out have proved to be species or strain-specific (Eisenstark \& Bernstein, 1955; Klement \& Lovas, 1960). By contrast, phages for plant pathogenic species of Pseudomonas may show cross-reaction with other species and with green-fluorescent soil pseudomonads (Stolp, 1961). However, most of Stolp's phages were isolated from soil rather than from plant material. Billing (1963) found that, whereas the majority of plant pathogens that she examined were lysed by one or more of the phages isolated from different sources using plant pathogens as propagating strains, Pseudomonas aeruginosa and many of the pseudomonads from sources other than plant material were not. One of the phages isolated by Billing from plant material lysed many plant pathogenic species of Pseudomonas but none of the isolates from soil and water. However, it is apparent from the work of Klement \& Lovrekovich (1960) that phages for plant pathogenic species of Pseudomonas cross-react with other plant pathogens of this genus more frequently than do phages for species within the genus Xanthomonas.

The use of phages obtained from lysogenic strains of Xanthomonas malvacearum or of phages from sources other than bacterial blight-infected cotton material may serve to differentiate strains within groups 1 and 2, and such work should be carried out because of possible correlation with differences in the reaction of cotton varieties. Inoculation experiments done in Tanganyika (Cross, 1963, and personal communication) showed that there are differences in varietal reaction between group 1 and group 2 isolates, but group 2 isolates show pathogenic variability. All the United States isolates examined so far have been classified into group 2; they include ATcc no. 9924, 12131, 12132 and eleven collections of plant material infected with physiologic races of $X$. malvacearum (including the races 1, 2, 4, 6, 10 of Brinkerhoff, 1963). The pathogenic variability of group 1 has yet to be determined. Preliminary work has indicated the utility of phage-sensitivity tests in an epidemiological investigation (Hayward, 1963). Knowledge of the distribution of groups 1 and 2 is at present incomplete. Collections from three widely separated areas in Australia have proved to be group 2. In the Republics of Mali and the Sudan both groups have been found; similarly in Tanganyika, Uganda and Northern Nigeria. Group 1, but not 2, has been obtained from Northern Rhodesia, Nyasaland, Ceylon and Thailand, but the number of collections examined from these areas is too small for any firm conclusion to be drawn at present. 
The characteristics of Xanthomonas malvacearum described above are in general similar to those of most Xanthomonas species. According to Dye (1962), who has made a survey of the genus, laboratory methods are of little value for the identification of the innumerable species in this genus. However, the present work suggests that examination of isolates of one species from many parts of the world can give information of use in epidemiological investigations and even lead, as in this case, to the delineation of subspecific taxa differing consistently in phage sensitivity and in biochemical characters readily determinable in the laboratory.

I am greatly indebted to members of the staff of the Empire Cotton Growing Corporation for collections of bacterial blight on cotton, in particular J. E. Cross (Tanganyika), M. H. Arnold (Uganda), N. L. Innes (Sudan), M. Dransfield (Northern Nigeria), and K. R. M. Anthony (Thailand). I am also grateful to Professor L. A. Brinkerhoff (Oklahoma State University) and Dr L. S. Bird (Texas A. and M. College) for United States material; to J. J. Basinski (C.S.I.R.O., Canberra) for Australian collections, and Dr R. Lagière (I.R.C.T., Paris) for many African collections. I am grateful to C. Logan for three bacteriophages and their propagating strains.

\section{REFERENCES}

Billing, E. (1963). The value of phage sensitivity tests for the identification of phytopathogenic Pseudomonas spp. J. appl. Bact. 26, 193.

BrinkerhoFf, L. A. (1963). Variability of Xanthomonas malvacearum: the cotton bacterial blight pathogen. Tech. Bull. Okl. agric. Exp. Sta. T-98.

Christensen, W. B. (1946). Urea decomposition as a means of differentiating Proteus and paracolon cultures from each other and from Salmonella and Shigella types. J. Bact.52, 461.

Cross, J. E. (1963). Pathogenicity differences in Tanganyika populations of Xanthomonas malvacearum. Emp. Cott. Grow. Rev. 40, 125.

Crosse, J. E. \& Hingorani, M. K. (1958). A method for isolating Pseudomomas morsprunorum phages from the soil. Nature, Lond. 181, 60.

DYE, D. W. (1962). The inadequacy of the usual determinative tests for the identification of Xanthomonas spp. N.Z. J. Sci. 5, 393.

Eisenstark, A. \& Bernstein, L. B. (1955). Specificity of bacteriophages of Xanthomonas pruni. Phytopathology, 45, 596.

Frazier, W. C. (1926). A method for detecting changes in gelatin due to bacteria. J. infect. Dis. 39, 302.

Hayward, A. C. (1960). A method for characterizing Pseudomonas solanacearum. Nature, Lond. 186, 405.

Hayward, A. C. (1962). Studies on bacterial pathogens of sugar cane. Occ. Pap. Sug. Ind. Res. Inst. Mauritius, no. 13, pp. 1-27.

HAYwARD, A. C. (1963). A note on bacteriophage typing of African strains of Xanthomonas malvacearum. Emp. Cott. Grow. Rev. 40, 216.

Hayward, A. C. \& Hodgkrss, W. (1961). Taxonomic relationships of Xanthomonas uredovorus. J. gen. Microbiol. 26, 133.

Katzenson, H. \& Sutron, M. D. (1951). A rapid phage plaque count method for the detection of bacteria as applied to the demonstration of internally borne bacterial infections of seed. J. Bact. 61, 689 .

KLEment, Z. (1957). Two new bacteriophages for bacterial pathogens of the bean. Nature, Lond. 180, 41.

KLEMENT, Z. (1959). Some new specific bacteriophages for plant pathogenic Xanthomonas spp. Nature, Lond. 184, 1248. 
Krement, Z. \& Lovas, B. (1960). Biological and morphological characterization of the phage for Xanthomonas phaseoli var. fuscans. Phytopath. Z. 37, 321.

KLement, Z. \& Lovrekovich, L. (1960). Identification of phytopathogenic bacteria by means of phages. Report of Conference on Scientific Problems of Plant Protection, Budapest, 1960, p. 187 .

Kovacs, N. (1956). Identification of Pseudomonas pyocyanea by the oxidase reaction. Nature, Lond. 178, 703.

LAGIìre, R. (1960). La bactériose du cotonnier, Xanthomonas malvacearum (E. F. Smith) Dowson, dans le monde et en Republique Centrafricaine (Oubangui-Chari). Observations et recherches. Paris: Institut de Recherches du Coton et des Textiles Exotiques.

MandelL, J. D. \& Eisenstark, A. (1953). Factors affecting plaque formation by Xanthomonas pruni bacteriophage. Phytopathology, 43, 27.

Rosberg, D. W. \& Parrack, A. L. (1955). The electron microscopy of a bacteriophage attacking Xanthomonas malvacearum. Phytopathology, 45, 49.

SrknRA, G. (1957). A simple method for the detection of lipolytic activity of microorganisms and some observations on the influence of contact between cells and fatty substrates. Antonie van Leeuwenhoek, 23, 15.

SToup, H. (1961). Neue Erkenntnisse über phytopathogene Bakterien und die von ihnen verursachten Krankheiten. Phytopath. Z. 42, 197.

Sutron, M. D., Katznelson, H. \& Quaduing, C. (1958). A bacteriophage that attacks numerous phytopathogenic Xanthomonas spp. Can. J. Microbiol. 4, 493.

Sutron, M. D. \& Katznelson, H. (1953). Isolation of bacteriophages for the detection and identification of some seed-borne pathogenic bacteria. Can. J. Bot. 31, 201. 